\title{
Engineering Properties of Some Sedimentary Rocks at the Proposed Qomroud Tunnel Project Lot No. 7 in Iran
}

\author{
A. Shafiei University of Waterloo, Canada \\ M.B. Dusseault University of Waterloo, Canada
}

\begin{abstract}
Vast areas in central Iran have suffered from water shortages for many decades due to limited water resources in the country. The Qomroud Tunnel Project Lot number 7 (QTP7), which is the subject of this study, is part of the Dez-Qomroud water conveyance tunnel projects that will convey water from the adjacent Dez Highlands to a central Iran watershed known as Qomroud. Comprehensive engineering geology and rock mechanics studies have been conducted to determine geological-geomechanical characteristics of the geological strata along the QLT7 tunnel route. Results from these field and laboratory tests are presented and discussed in this article.
\end{abstract}

\section{Introduction}

Vast areas in central Iran have suffered from periodical water shortages for many decades due to limited water resources. Supplying sufficient water for both drinking and irrigation purposes is one of the great challenges that the Iranian water supply industry is facing over the coming years. The Qomroud tunnel project will convey $21 \mathrm{~m}^{3} / \mathrm{sec}$ of water from the adjacent Dez Highlands to a central Iran watershed known as Qomroud; it involves four tunnels, three small dams and a large dam. The Qomroud Tunnel Project Lot number 7 (QTP7), which is the subject of this study, is part of the Dez-Qomroud water conveyance tunnel project.

The proposed QTP7 tunnel route is situated in the Zagros tectonically disturbed zone in west central Iran, Lorestan province. Based on field engineering geological studies, the main strata along the proposed QTP7 tunnel route consists of marly limestone of the Surmeh formation and massive brown to grey limestone of the Fahliyan formation. The depth of the tunnel ranges from 20 to $185 \mathrm{~m}$. Comprehensive engineering geology and rock mechanics studies have been conducted in the area to determine the geologicalgeomechanical characteristics of the rock masses along the tunnel route.

To ensure the permanent stability of the tunnel, choose the excavation method and design the required type of the support, the first task is to investigate the characteristics of the ground. The litho-mechanical characterisation of the rocks included conducting comprehensive rock mechanics studies in the study area including surface geology, jointing fabric study, borehole drilling and logging, and field and laboratory geotechnical testing. Laboratory tests on core samples were carried out to delineate the physical and geomechanical properties of the intact rock at the tunnel site. For the different rock units exposed in the study area, physical and geomechanical properties such as dry density, saturated density, porosity, durability index, uniaxial compressive strength (UCS), shear and compressional wave propagation velocity (VS, VP), and water absorption ratio were determined in the laboratory based on ASTM (1993) standards and ISRM (1981) suggested methods.

In this article, first the geological setting of the QTP7 tunnel project and the engineering geology and rock mechanics studies program conducted in the study area are presented. In this stage, the QTP7 tunnel route is divided into a few geomechanical units (GMUs). For engineering analysis, each rock mass must be divided into a tractable number of GMUs in order to ease the problem of rock characterisation. Each GMU is distinct from other GMUs in the rock mass (e.g. through layering, fault separation or litho-mechanical contrasts) and has its own geomechanical characteristics. Then results from these comprehensive laboratory tests are presented, analysed and discussed here for each defined GMU along the QTP7 tunnel project. Some 
interrelationships between physical and mechanical properties of the tested intact rock samples taken from each GMU are presented and discussed as well.

\section{Geological setting}

As discussed earlier in this text, the QTP7 tunnel project is designed as part of the Qomroud Long Tunnel projects which will transfer over $650,000,000 \mathrm{~m}^{3}$ of water per year to the central part of Iran for both drinking and irrigation purposes. Central Iran can be described as an arid area with very limited water supply. Providing enough water to this area is a great challenge for the Iranian water supply industry. To help resolve this issue, a project known as the Dez-Qomroud will convey water from the adjacent Dez Highlands to the central Iran water-shed; it involves four tunnels (total length of $54 \mathrm{~km}$ ), three small dams and a large dam. The QTP 7, inlet front, is located $65 \mathrm{~km}$ south of Aligoudarz-Isfahan road, accessed by the Shoul-Abad road from Aligoudarz town, Lorestan province, west central Iran (Figure 1). Overall layout of the Qomroud Tunnel projects is shown in Figure 1. In this section, engineering geology and stratigraphy of the QTP7 tunnel project is described.

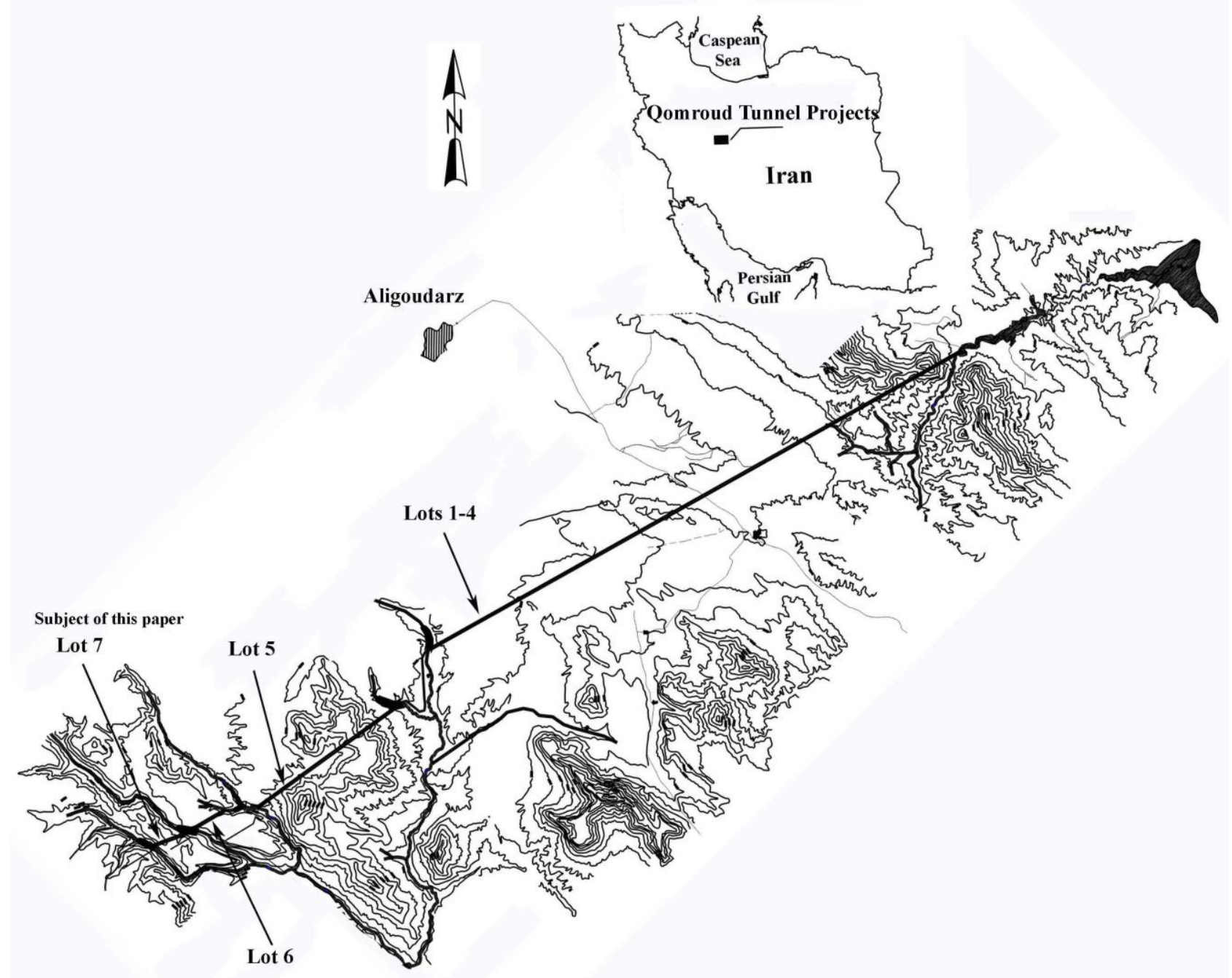

Figure 1 Geographical location and layout of the Qomroud water transfer tunnel projects in Iran 


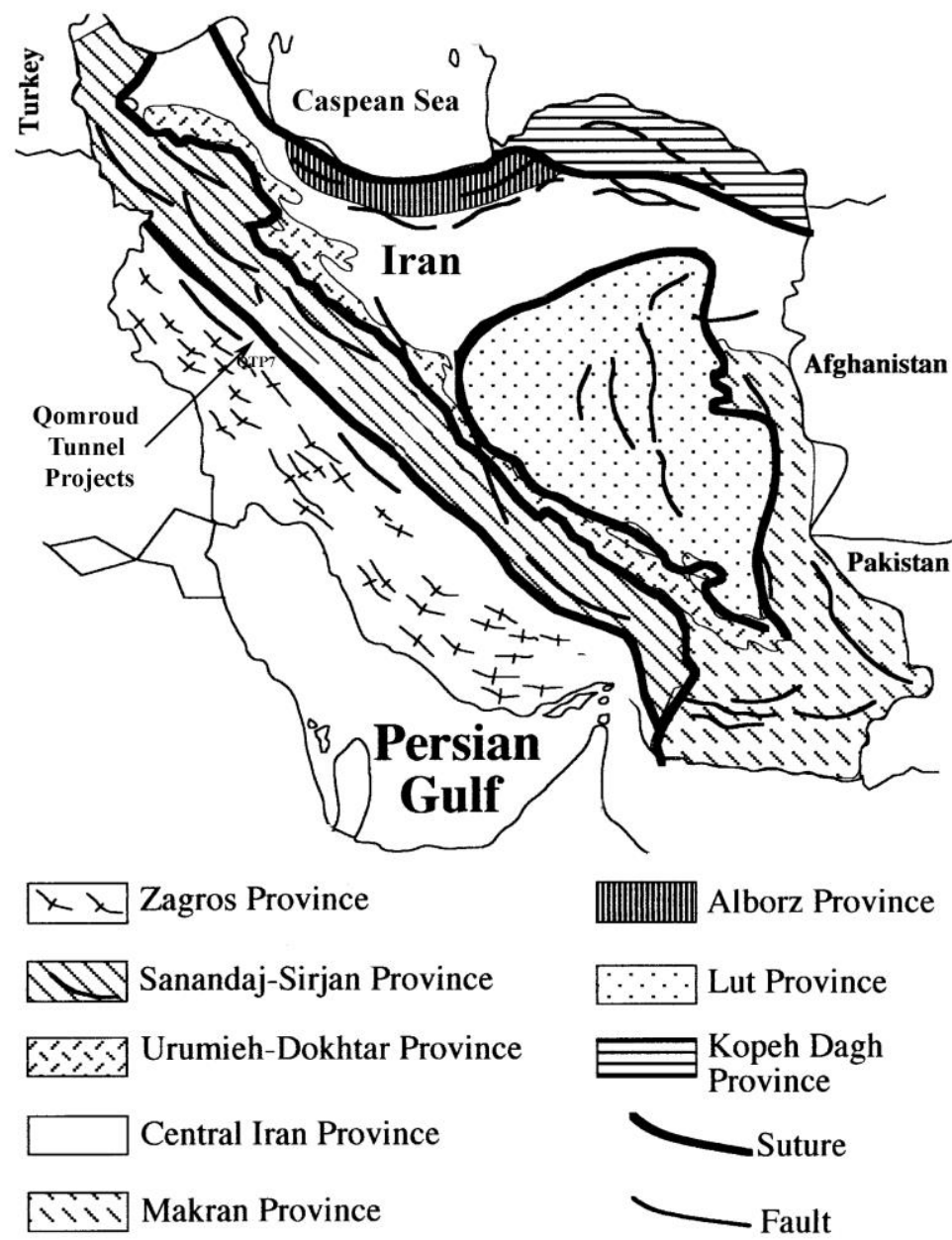

Figure 2 The study area in the Sanandaj-Sirjan zone

Stocklin (1968) defined five major geological zones in Iran, based on geological, structural and sedimentological features (Figure 2). Berberain (1995) subdivided the Zagros geological province into five morphotectonic sub-zones based on differences in topography, seismicity, stratigraphy and deformation style. These sub-zones of the Zagros geological province are separated by large-scale thrust faults that create asymmetric topographic patterns. The proposed QTP7 tunnel project is situated in the Zagros Crushed zone a tectonically disturbed zone in west central Iran, Lorestan province. The Zagros Crushed zone sub-zone is surrounded by the Main Zagros Reverse fault and the Sanandaj-Sirjan zone. Based on field engineering geological studies, the main strata exposed along the proposed QTP7 tunnel area consist of marly limestone and dolomite of Surmeh formation, a Lower to Upper Jurassic age formation, and massive brown to grey limestone of Fahliyan formation, a Tithonian to Hauterivian age formation (Uppermost Jurassic-Cretaceous) (Alavi, 2004). In the study area, Bakhtiari formation conglomerate, a Pliocene to Pleistocene age synorogenic coarse-grained mud-supported brown conglomerate overlies the Fahliyan formation with an angular unconformity. This rock unit has a maximum thickness of about $200 \mathrm{~m}$ in the study area, and it is formed of limestone, marly limestone and radiolarite rock fragments in a clay cement (Bakhtiari Conglomeratic formation). A simplified geological profile along the QTP7 tunnel project based on the primary engineering geological studies is shown in Figure 3.

\section{Geotechnical investigations}

The detailed tunnel axis investigations at the QTP7 tunnel site mainly included discontinuity surveying, core drilling, in situ and laboratory testing. In this section, results from the drilling program and laboratory test data from specimens taken from core samples will be presented and discussed. 


\subsection{Geotechnical drilling program}

After selection of the QTP7 tunnel route from reconnaissance phase studies, drilling was carried out at the site, along the axis of the proposed tunnel route to provide the subsurface conditions and to obtain rock samples for laboratory testing purposes. A total of three vertical boreholes with $400 \mathrm{~m}$ in aggregate length were drilled using rotary drilling equipment. Rock quality designation (RQD) values of the rock masses were determined.

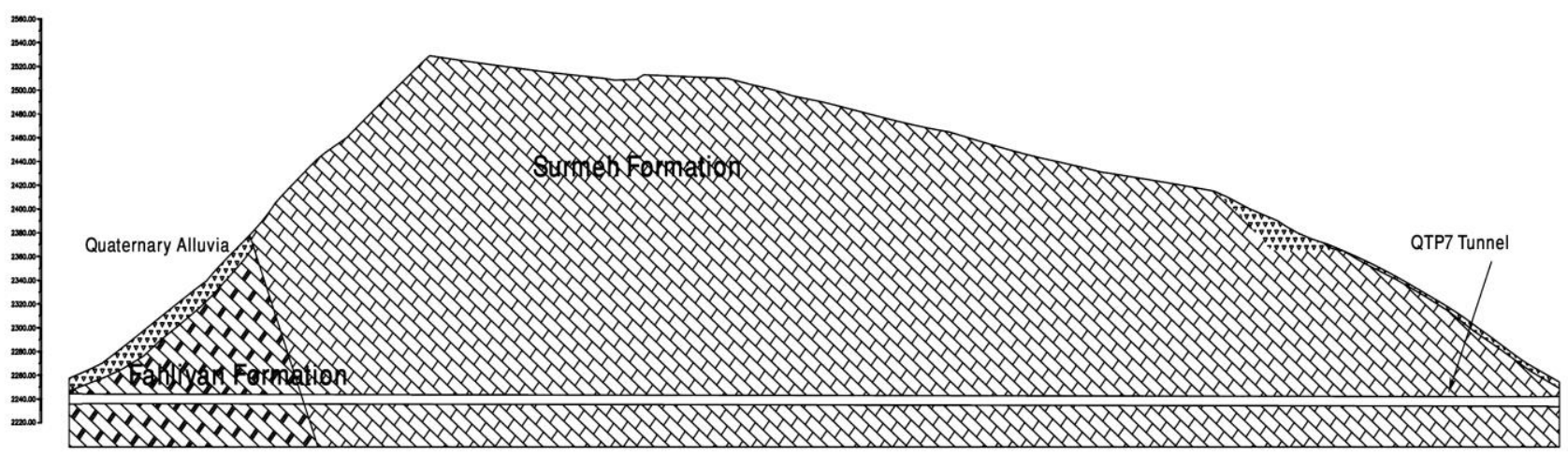

\section{Figure 3 Geological profile along the QTP7 tunnel project}

In a rock mass, a group of rock types with similar litho-stratigraphical and structural features are often defined as a single GMU. For engineering analysis, each rock mass must be divided into a tractable number of GMUs in order to ease the problem of rock mass characterisation. Each GMU is distinct from other GMUs in a rock mass (e.g. through layering, fault separation or litho-mechanical contrasts) and has its own geomechanical characteristics. Two GMUs have been identified along the QTP7 tunnel route.

Because of the relatively simple geology of the study area along the selected tunnel route in terms of the lithology, comprising just two geomechanical units (the Surmeh and Fahliyan formations), results from any field and laboratory geotechnical investigation could be applied to other nearby rocks in case of any significant change in the selected QTP7 tunnel route. We abbreviated these two GMUs with S (the Surmeh formation) and $\mathrm{F}$ (the Fahliyan formation) for the rest of the article.

High quality cores obtained from these three drilled vertical boreholes were tested in a rock mechanics laboratory and the drill holes were used for in situ tests, such as water pressure testing for permeability. The depth of the water table in the boreholes was recorded for hydro-geological studies and to monitor any water table fluctuations. A simplified geological profile along the QTP7 tunnel project based on the primary engineering geological studies is shown in Figure 3.

According to the drilling reports, $\sim 56 \%$ of the QTP7 tunnel passes through the S geomechanical unit with thickness of 20 to $300 \mathrm{~m}$ along the tunnel path. Also, the F geomechanical unit with thickness of 15 to $120 \mathrm{~m}$ constitutes $\sim 44 \%$ of the tunnel path. Based on the drilling reports, RQD values along the QTP7 tunnel route for the S and F GMUs vary between 60 to $85 \%$ and 45 to $60 \%$, respectively.

\subsection{Laboratory tests}

Laboratory experiments were carried out on core specimens of the S and F GMUs to determine the physical and geomechanical properties of rock samples taken from the study area. These GMUs were tested for physical parameters such as dry and saturated density, porosity, water absorption ratio, and geomechanical properties such as uniaxial compressive strength, compressional and shear wave propagation velocity, Brazilian tensile strength, slake durability test and deformation parameters. Test results for the studied geomechanical units are summarised and presented in Table 1. Laboratory tests performed to determine the geotechnical parameters of different GMUs were based on ASTM (1993) standards and ISRM (1981) suggested methods. Results quoted are for a minimum of 10 specimens in each case. 


\subsubsection{Uniaxial compressive strength and the Brazilian tensile strength}

The UCS test method is intended to measure the uniaxial compressive strength of a rock sample with a regular cylindrical geometry. The test is mainly intended for strength classification and characterisation of intact rock. As shown in Table 1, the uniaxial compressive strength values for the $\mathrm{S}$ and $\mathrm{F}$ GMUs are 26 to $85 \mathrm{MPa}$ and 16 to $30 \mathrm{MPa}$, respectively. These are wide ranges of values, reflecting the heterogeneity. Brazilian tensile strength obtained in this study varies between 2.17 to 8.50 and 1.90 to $2.30 \mathrm{MPa}$ for the S and F GMUs, respectively.

Table 1 Physical and geomechanical properties of the rock materials along the QTP7 tunnel route

\begin{tabular}{ccccccccccc}
\hline $\mathrm{GMU}$ & $\rho^{\mathrm{s}}\left(\mathrm{g} / \mathrm{cm}^{3}\right)$ & $\begin{array}{c}\rho_{\mathrm{d}} \\
\left(\mathrm{g} / \mathrm{cm}^{3}\right)\end{array}$ & $\mathrm{W}_{\mathrm{a}} \%$ & $\mathrm{n}$ & $v$ & $\sigma_{\mathrm{t}}(\mathrm{MPa})$ & $\mathrm{E}(\mathrm{GPa})$ & $\sigma_{\mathrm{c}}(\mathrm{MPa})$ & $\mathrm{V}_{\mathrm{s}}(\mathrm{km} / \mathrm{s})$ & $\mathrm{V}_{\mathrm{p}}(\mathrm{km} / \mathrm{s})$ \\
\hline $\mathrm{S}$ & 2.67 & 2.66 & 5 & 0.70 & 0.25 & $2.17-8.50$ & $4-9$ & $26-85$ & $2.60-3.80$ & $3.60-6.70$ \\
\hline $\mathrm{F}$ & 2.68 & 2.67 & 15 & 0.89 & 0.20 & $1.90-2.30$ & $3-5.5$ & $16-30$ & $2.10-3.70$ & $3.70-5.60$ \\
\hline
\end{tabular}

The ratio of UCS: UTS is about 0.10 and 0.14 for the S and F GMUs, respectively, which is a typical number for these types of rocks.

\subsubsection{Slake durability index}

Franklin and Chandra (1972) suggested a slake durability index to assess the resistance offered by a rock sample to weathering and disintegration when subjected to two standard cycles of drying and wetting. Slake durability indices are based on the classification schemes of Gamble (1971) and Franklin and Chandra (1972). Slake durability indices vary between 97 to $99 \%$ for the tested samples taken from both S and F GMUs.

The effect of porosity on UCS (expressed in MPa), compressional wave propagation velocity $\left(\mathrm{V}_{\mathrm{P}}\right)$ and Young's modulus of elasticity (E - in GPa) of the studied geomechanical units, the S and F GMUs, was explored through simple plots. The relationships between these parameters are presented in Figures 4 to 6. It is logical, and confirmed by the plots, that with an increase of porosity for all of the tested rocks there is a decrease in uniaxial compressive strength, elastic modulus and P-wave propagation velocity values. Figure 7 presents a relationship between the uniaxial compressive strength UCS (MPa) and the elasticity modulus (GPa). As can be seen, in general, the elastic modulus of the tested rock samples increases with increasing rock strength, which is a well known empirical relationship and widely used in engineering geology.

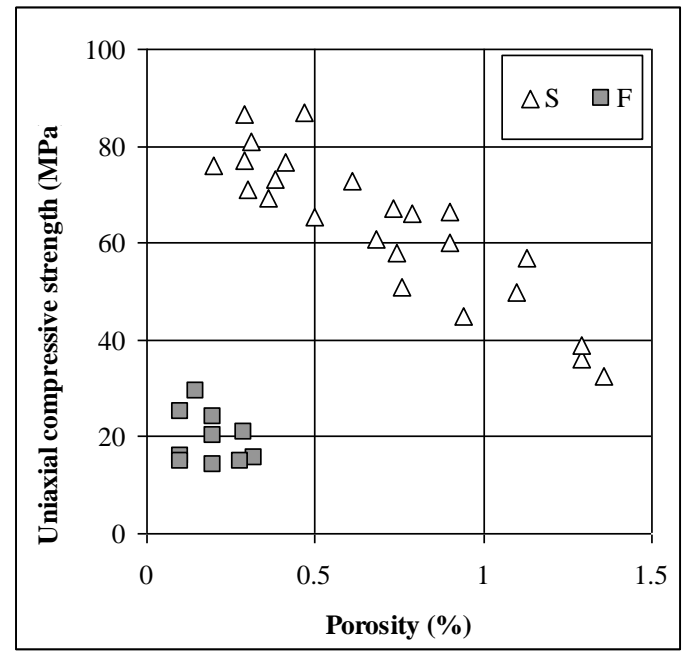

Figure 4 Relation between porosity (\%) and uniaxial compressive strength (MPa) for two studied geomechanical units, $S$ and $F$, at the QTP7 tunnel site 


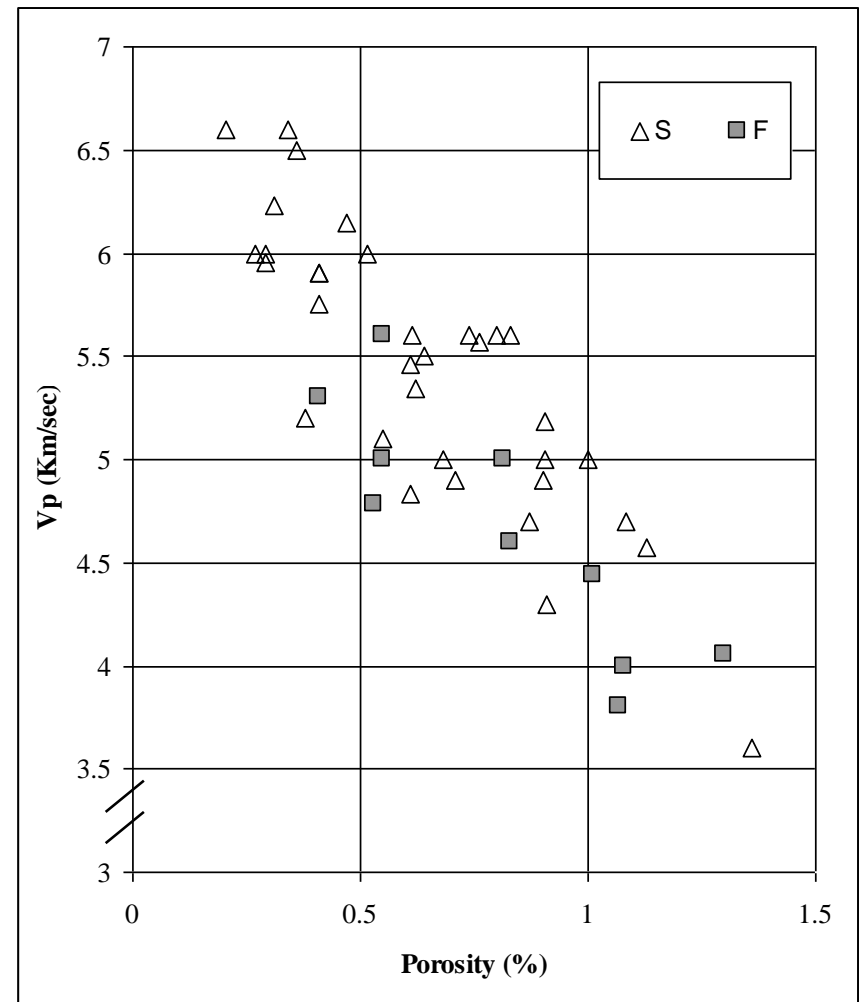

Figure 5 Relation between porosity (\%) and primary wave velocity (VP), $(\mathrm{km} / \mathrm{sec})$ for two studied geomechanical units, $S$ and $F$, at the QTP7 tunnel site

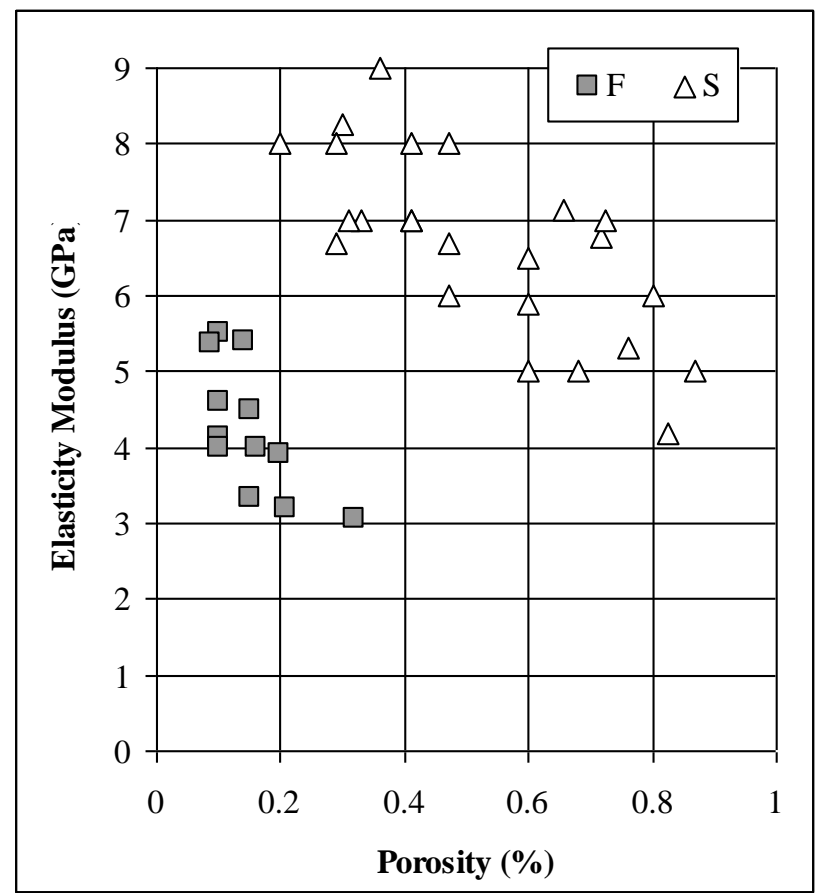

Figure 6 Relation between porosity (\%) and elasticity modulus (MPa) for two studied geomechanical units, $S$ and $F$, at the QTP7 tunnel site 


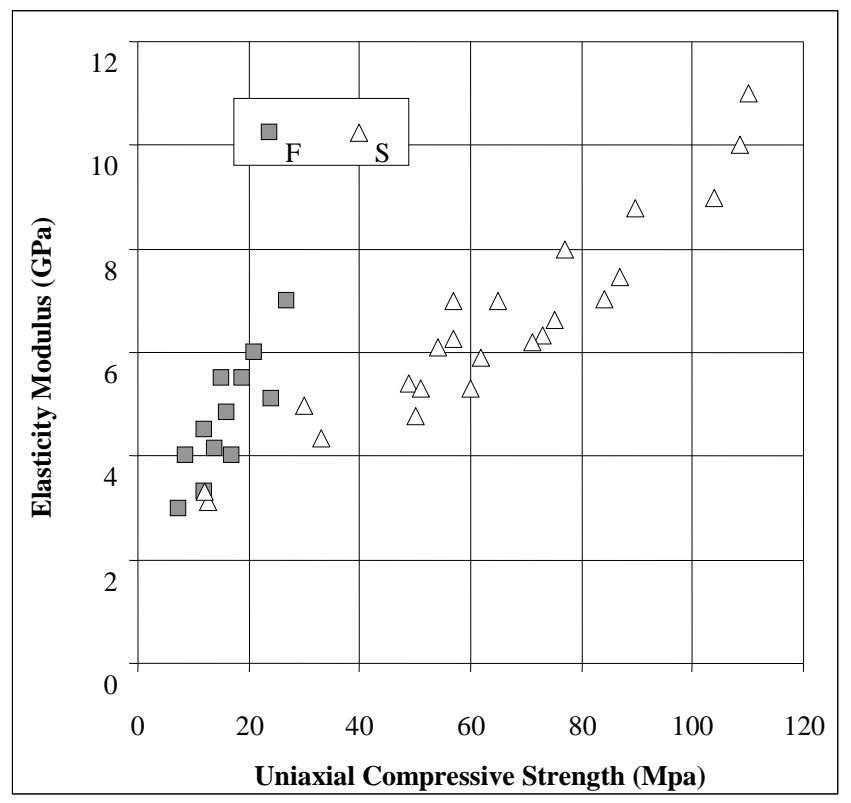

Figure 7 Relation between uniaxial compressive strength (MPa) and elasticity modulus (MPa) for two studied geomechanical units, S and F, at the QTP7 tunnel site

\section{Summary and discussion}

The QTP7 tunnel path is composed of sedimentary rocks, divided into two GMUs, the Surmeh formation (S), marly limestone and dolomite, and the Fahliyan formation, massive brown to grey limestone.

Three vertical boreholes drilled on the QTP7 tunnel axis to provide the subsurface conditions and to obtain rock samples for laboratory testing purposes. The RQD index for each rock mass at the QTP7 tunnel route was determined based on the criteria of Deere et al. (1966). From the RQD index thus obtained, the S and F GMUs would be classified as of fair to good and poor to fair rock mass quality, respectively.

Laboratory tests on core samples were carried out to find the physical and geomechanical properties of the intact rock at the QTP7 tunnel site. Based on laboratory results (Table 1), the dry density of rock samples from $\mathrm{S}$ and $\mathrm{F}$ geomechanical units is 2.66 and 2.67, respectively. According to classification of Anon (1979), the $\mathrm{S}$ and F GMUs settle in the category of rocks with high dry density.

Porosity of the tested samples taken from $\mathrm{S}$ and $\mathrm{F}$ geomechanical units varies between 0.70 and $0.89 \%$, respectively. Based on Anon (1979) these tested samples can be classified as low porosity rocks.

Based on results from uniaxial compression tests, as shown in the Table 1, the $\mathrm{S}$ and $\mathrm{F}$ geomechanical units are classified as moderately strong to strong and moderately strong rock groups, respectively, according to Anon (1979). Also, they can be classified as low to medium strength and very low to low strength rock groups, respectively, based on the classification for rock material strength proposed by Deere and Miller (1966).

Elasticity moduli of the tested rock sample taken from S and F geomechanical units vary between four and nine and 3 to $3.50 \mathrm{GPa}$, respectively. They can be classified as rock groups with very high to high and very high deformability based on Anon (1979).

Franklin and Chandra (1972) suggested a slake durability index to assess the resistance offered by a rock sample to weathering and disintegration when subjected to two standard cycles of drying and wetting. Slake durability indices are based on the classification schemes of Gamble (1971) and Franklin and Chandra (1972). Slake durability indices vary between 97 to $99 \%$ for the tested samples taken from both S and F GMUs, respectively; which show the retained weight $\%$ after two $10 \mathrm{~min}$ cycles, on a dry weight basis. Based on Gamble's proposed slake durability classification (Goodman 1980; Gamble, 1971), the tested rock samples from the $\mathrm{S}$ and F GMUs have medium high to high durability. 
Based on laboratory results, shown in the Table 1, mean compressional and shear wave propagation velocities of 3.60 to 6.70 and 2.60 to $3.80 \mathrm{~km} / \mathrm{sec}$ in a saturated condition were measured for the S GMU, respectively. These parameters for the F GMU are 3.70 to 5.60 and 2.10 to $3.70 \mathrm{~km} / \mathrm{sec}$, respectively.

It should be noted that the designers decided to relocate the tunnel route based on the comprehensive engineering geological investigations and identification of a heavily crushed zone (fault zone), (Figure 8) at the inlet of the QTP7 tunnel route. The new route of QTP7 is about 200 to $250 \mathrm{~m}$ away from the originally investigated route and $200 \mathrm{~m}$ longer than the original proposed route, but will escape the fault zone and pass through a very high quality limestone of S GMU.

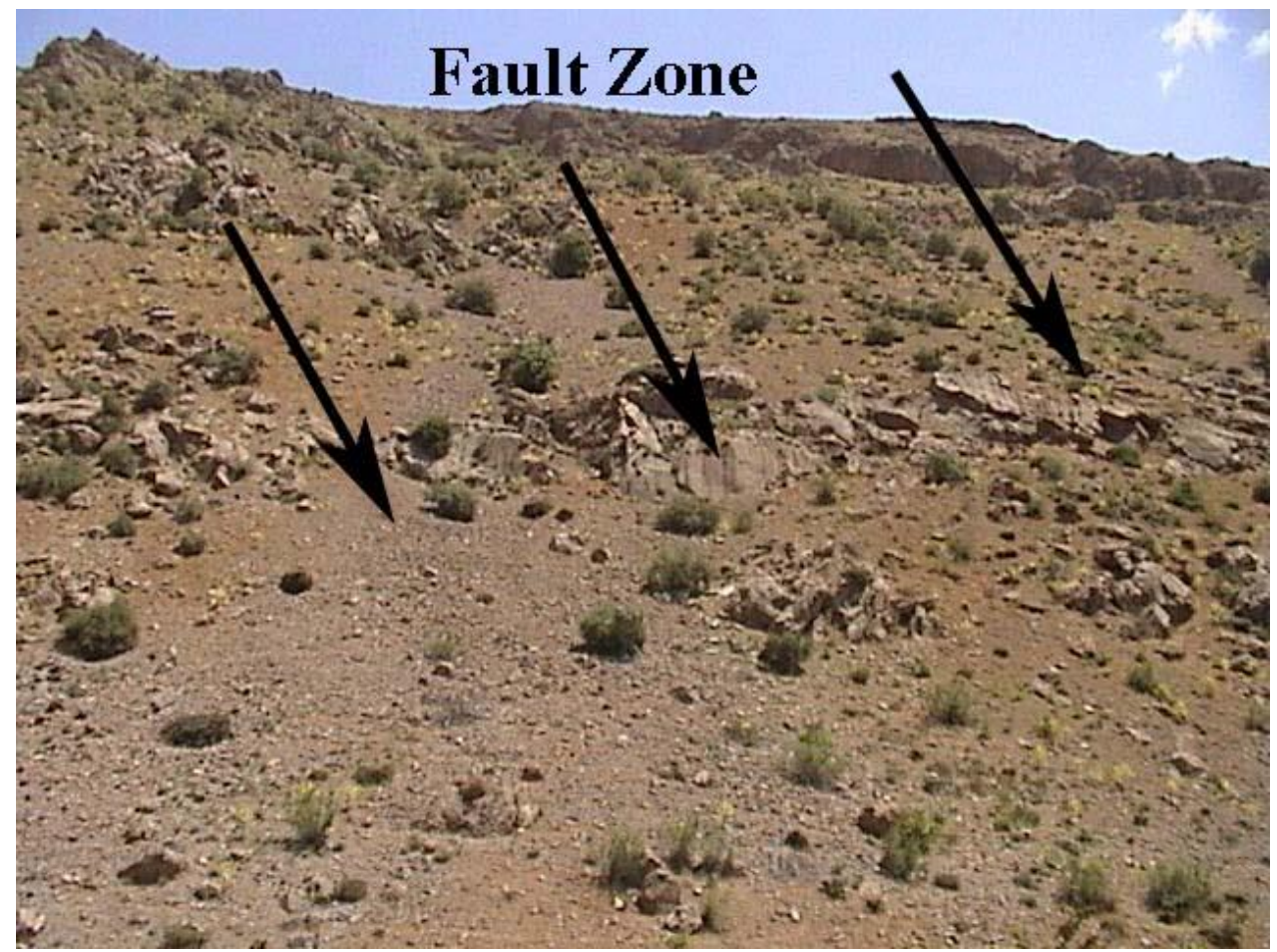

\section{Figure 8 A heavily crushed fault zone, located at the inlet of the QTP7 tunnel route based on preliminary engineering geological investigations}

Initially QLT6 was supposed to serve as a water conveyance tunnel and a transportation tunnel with a final diameter of $10 \mathrm{~m}$ and area of $65 \mathrm{~m}^{2}$. Considering results from this study, the designers decided to reduce the diameter of the tunnel to $4.5 \mathrm{~m}$ with an area of $26 \mathrm{~m}^{2}$ in order to reduce the risk of tunnel instability, ease the tunnel excavation and reduce the support cost.

QTP7 was excavated successfully using drill and blast technique taking into account engineering geological considerations, partly discussed herein. Excavation of QLT6 was completed in February 2008, lining and contact and consolidation grouting operations are underway right now. The QTP7 tunnel project and its diversion embankment dam will be completed in late 2008, to serve as part of the Dez-Qomroud water conveyance tunnel projects.

\section{Conclusions}

Two geomechanical units (GMUs) have been identified at the QTP7 tunnel site; they have been extensively tested in the laboratory.

Physical and geomechanical tests were carried out on specimens obtained from boreholes drilled in the tunnel path. Based on results from uniaxial compression tests, as shown in the Table 1 , the $\mathrm{S}$ and $\mathrm{F}$ geomechanical units are classified as moderately strong to strong and moderately strong rock groups, respectively, according to Anon (1979). Also, they can be classified as low to medium strength and very low to low strength rock groups based on the classification for rock material strength proposed by Deere and Miller (1966). 
- Elasticity moduli of the tested rock sample taken from $\mathrm{S}$ and $\mathrm{F}$ geomechanical units vary between four to nine and 3 to $3.50 \mathrm{GPa}$, respectively. They can be classified as rock groups with very high to high and very high deformability based on Anon (1979).

- Slake durability indices vary between 97 to $99 \%$ for the tested samples taken from both S and F GMUs, respectively. Based on Gamble's proposed slake durability classification (Goodman 1980; Gamble, 1971), the tested rock samples from the S and F GMUs have medium high to high durability.

- Mean compressional and shear wave propagation velocities of 3.60 to 6.70 and 2.60 to $3.80 \mathrm{~km} / \mathrm{sec}$ in a saturated condition were measured for the S GMU, respectively, based on laboratory results (Table 1). These parameters for the F GMU are 3.70 to 5.60 and 2.10 to $3.70 \mathrm{~km} / \mathrm{sec}$, respectively.

- The RQD index for each rock mass at the QTP7 tunnel route was determined based on the criteria of Deere et al. (1966). From the RQD index thus obtained, the $S$ and F GMUs would be classified as of fair to good and poor to fair rock mass quality, respectively.

- Based on laboratory results (Table 1), the dry density of rock samples from $\mathrm{S}$ and $\mathrm{F}$ geomechanical units is 2.66 and 2.67, respectively. According to classification of Anon (1979), the S and F GMUs settle in the category of rocks with high dry density.

Engineering geological investigations, field and laboratory test results and computations indicate that the QTP7 tunnel route, as currently proposed, can be safely constructed on the site studied. Furthermore, during the design phase, a more detailed engineering geology investigation focusing on particular details of tunnel sections is needed. The importance of geological detail and of a broad assessment of all relevant mechanisms in site selection for hydraulic structures is paramount.

\section{Acknowledgements}

Ali Shafiei would like to thank his previous co-workers in the Dez-Qomroud project in Iran, especially H. Rahdar for his invaluable support and encouragement.

\section{References}

Alavi, M. (2004) Regional stratigraphy of the Zagros folded-thrust belt of Iran and its proforeland evolution. American Journal of Science 304, pp. 1-20.

Anon (1979) Classification of rocks and soils for engineering geological mapping part 1: Rock and soil materials. Bulletin of International Association of Engineering Geology 19, pp. 355-371.

ASTM (1993) Annual book of ASTM standards. American Society of Testing and Materials, West Conshohocken, Pennsylvania.

Berberian, M. (1995) Master blind thrust faults hidden under the Zagros folds: active basement tectonics and surface morphotectonics. Tectonophysics 241, pp. 193-224.

Deere, D.U. and Miller, R.P. (1966) Engineering classification and index properties of rock. Technical Report No. AFNL-TR-65-116. Albuquerque, New Mexico: Air Force Weapons.

Deere, D.U., Hendron, A.J., Patton, F.D. and Cording, E.J. (1966) Design of surface and near surface construction in rock. Proceedings 8th US Symposium On Failure and Breakage of Rock.

Franklin, J.A. and Chandra, R. (1972) The slake durability test. International Journal of Rock Mechanics and Mining Sciences 9, pp. 325-341.

Gamble, J.C. (1971) Durability-plasticity classification of shales and other argillaceous rocks. PhD Thesis. University of Illinois, Chicago.

Goodman, R.E. (1980) Introduction to Rock Mechanics. John Wiley and Sons. USA.

ISRM (1981) Suggested methods for rock characterization, testing and monitoring ISRM commission on testing methods. E.T. Brown (editor). Oxford: Pergamon.

Stocklin, J. (1968) Structural history and tectonics of Iran: A review. AAPG Bulletin 52, pp. 1229-1258. 


\section{Nomenclature - Acronyms}

$\mathrm{d}=$ dry

$\mathrm{s}$ = saturated

Symbols: Latin, then Greek

$\mathrm{E}=$ Young's modulus in static state (GPa)

$\mathrm{V}_{\mathrm{p}}=$ primary wave velocity $(\mathrm{km} / \mathrm{s})$

$\mathrm{V}_{\mathrm{s}}=$ secondary wave velocity $(\mathrm{km} / \mathrm{s})$

$\mathrm{W}_{\mathrm{a}}=$ water absorption $(\%)$

$\rho=\operatorname{density}\left(\mathrm{g} / \mathrm{cm}^{3}\right)$

$\sigma_{\mathrm{c}}=$ uniaxial compressive strength of intact rock (MPa)

$\sigma_{\mathrm{t}}=$ uniaxial tensile strength of intact rock (Brazilian) (MPa)

$\varphi=$ internal friction angle (degree) 